\title{
Appendix 6 \\ The text of the memory plaque
}

In eternal memory of our fellow humans who fell victim to fascist persecution on October 15, 1944

Braun Arthurné [Braun Asztrikné]

Faragó István

Faragó Istvánné

Faragó Lajos [correctly: István]

Grossmann Olga

Grünberger Ilona

Grünberger Margit

Grünberger Vilmos

Lichter Izrael

Mann Vilma

Singer Ernő

Steiner Andor

Steiner Béla

Steiner István

Steiner Lajos

Stern Ignác

Stern Ignácné

Takács Sándor

Tenczer Robert

Your sacrifice shows us the way towards building a free, happy Hungary. The tenants of the house. 